\title{
Management of Excreta and Parasitic Infestation of Ground and Children from 2 to 10 Years in Ngiri-Ngiri Health Area
}

\author{
Nadine Lulendo Masamba*, Patrick Senga Mutonkole, Guillaume Mbela Kiyomb and Joel Nkiama Konde
}

Institut Superieur des Techniques Medicales, Kinshasa, Democratic Republic of the Congo

\begin{abstract}
Population growth and increasing request of the consumer goods in urban centers represent certainly one of the causes at the base of the increase in the amount of waste. This is even more noticeable in Kinshasa, with its densely populated conurbations. This study aims to enhance the link (associations) between household excreta management mode and soil and children forme 2 to 10 years infestation. An analytical cross-sectional survey of 360 households was conducted in Kinshasa in order to determine helminth infections prevalence among targeted children and land plots. Willis flotation method and Ritchie enrichment were respectively used for soil and stool analysis. Chi-square test was used to detect a relationship or association with 0.05 significance level. Among surveyed households, $55.8 \%$ use latrines with effluents, including $34.5 \%$ evacuate their effluents either by cesspools or by using one or more hole (s) open (s) in plot and $29.9 \%$ by ditches. In addition, parasitic infestation prevalence of children from 2 to 10 years and land plots of Ngiri-Ngiri health zone is $61.2 \%$ and $44.8 \%$, respectively. This land use is associated with poor management of household excreta, and is an important risk factor for infestation.
\end{abstract}

Keywords: Excreta; Parasitic infestation; Children from 2 to 10 years; Soil; Ngiri-Ngiri

\section{Introduction}

The demographic explosion recorded over the last decades in Kinshasa resulted in a growing demand for consumer goods, which has led to increased production of solid, liquid and gaseous wastes. The permanent presence of these unrecognized resources in the urban environment constitutes a threat, causing several diseases [1]. Thus, resulting in the decrease in life expectancy of human population. Interest in waste management is evident and is observing in several researches, but also by the proliferation of international meetings of reflection revolving mainly around the environment and safety. Stockholm 1972, Kyoto 1977, Nairobi 1991, Rio de Janeiro 1992 and Johannesburg 2002 summits can be considered as those used engine about the awakening global consciousness on environmental issues [2].

Through various efforts around the world, it appears that the sanitation level is especially improving in developed countries. The case of some European countries that minimize spread risk of diseases that typically generate the excreta through the drain, transportation and disposal of sludge can be evoked [3]. France, one of the important countries of Europe, has 180,000 kilometers of pipeline as wastewater collection network. This device can now be connected to $79.4 \%$ of the French population drain. In parallel, a part of there or $19.3 \%$, however, has an independent drainage system and the rest $2.2 \%$ is neither connected nor equipped standalone installer [4]. By cons in developing countries, with a population of about 2.9 billion listed, only $20 \%$ are served by collection network and have septic tanks while $80 \%$ of people remain unserved. This induces the prevalence of infectious diseases such as diarrheal and parasitic diseases, especially in young children $[5,6]$.

One of the major concerns of African countries and more broadly the international community remains the problem of waste management. The solid and liquid wastes of various origins thrown haphazardly into the environment, cause enormous problems of hygiene and sanitation for people [5]. Moreover in the absence of adequate latrines and adequate waste management system in poor cities and high population density, it is observed the phenomenon of uncontrolled defecation which multiplies the gene sources and other infectious diseases [7]. Mutonkole et al. [8] evoke, for example, use of urban streams by Kinshasa population as receptacles of various waste types, including excreta. Because of such phenomenon, Perrine [9] observed a high prevalence of faecal-oral transmission diseases in Haiti and Mauritania.

However, Van Depite [10] and WHO [11] consider the Ascaris lumbricoides as, by far, the intestinal nematode parasiting the most people ( 1 billion), of which 20,000 die each year, mostly in developing countries. Address environmental hazards and risks, it proves that children present more vulnerability than adults, not only because their bodies are not fully developed, but also because they are in a dynamic process of growth and development. Their vulnerability exposes them to ingest the eggs of such parasites when in contact with contaminated land or food by human excreta [12]. In Malaysia, for example, AlMekhlafi [13] observed over $61.9 \%$ of children infected with Ascaris eggs and $98.2 \%$ by whipworms from households to contaminated soil. For the Democratic Republic of Congo (DRC), the situation is not encouraging with only $46 \%$ of population using hygienic toilets of which $61 \%$ are in Kinshasa [14]. The Arab pit is the most common type of latrine in the country with a low level of maintenance, which would increase the risk of spillover and scattering feces during intense rainfall [15]. Thus, the degraded state of global environment such as the Ngiri-Ngiri health area challenges our questioning in this: The socio-economic and demographic household level of Ngiri-Ngiri health zone allows it to face the challenge of managing excreta? The infestation of ground and children by Ascaris eggs, is-it associated with excreta management mode in households? Does the ground infestation contribute to the high rate of parasitoses infestation to children from 2 to 10 years? These questions summarize the purpose of this study that consists to highlight the relationship between the excreta management mode at the household level and infestation of soil and children from 2 to 10 years in Ngiri-Ngiri health area.

*Corresponding author: Nadine Masamba Lulendo, Institut Superieur des Techniques Medicales, Kinshasa, Democratic Republic of the Congo, E-mail: nadmasamba@gmail.com

Received June 08, 2016; Accepted July 20, 2016; Published July 25, 2016

Citation: Masamba NL, Mutonkole PS, Kiyomb GM, Konde JN (2016) Management of Excreta and Parasitic Infestation of Ground and Children from 2 to 10 Years in Ngiri-Ngiri Health Area. J Environ Anal Chem 3: 184. doi:10.417223802391.1000184

Copyright: ( 2016 Masamba NL, et al. This is an open-access article distributed under the terms of the Creative Commons Attribution License, which permits unrestricted use, distribution, and reproduction in any medium, provided the original author and source are credited. 


\section{Material and Methods}

\section{Study area}

Ngiri-Ngiri township current emanation, this health zone is one of the 35 health zones included in Kinshasa. It has an area of $3.5 \mathrm{~km}^{2}$ and a population density of 37,571 inhabitants per $\mathrm{km}^{2}[16]$. It is built on a periodically flood plain according to the average annual rainfall.

A study, both analytic cross sectional and simultaneous of household characteristics on the excreta management mode and soil and children from 2 to 10 years infestation was conducted between June and July 2008 in Ngiri-Ngiri health area.

\section{Sampling unit and statistical analysis}

Was considered in the study any household with at least one child from 2 to 10 years, which was selected by simple random sampling, also representative [17], for harvesting and stool examination. A composite soil sample [18] was also conducted for parasites detection in the laboratory according to Willis flotation method by enrichment in water saturated with $\mathrm{NaCl}$, whereas the analysis of stool samples by the direct method and that of Ritchie based on stool concentration [19]. In addition, 5 blocks per health area and 9 households per street were selected by using a sampling with probability proportional to the size. Data obtained by direct interview or structured interview were subdivided into slices ages of 2 to 4 years (unschoolchildren) and 5 to 10 years (schoolchildren). Only household head or his spouse, sometimes the child's guardian was asked for the interview.

In this study, apart from general informations about the household, the following variables were collected: selected child (s) age, schooling of children 2-10 years, parental education level, parental income, possession of latrines, type of latrine, drain mode of excreta and sewage, different types of parasites. Samples were kept according to Ref. [13].

Data obtained previously underwent pretreatment of elaborating an input mask on the data Epi 3.0. Software followed by descriptive statistics on certain quantitative variables like size of households, number of people per plot, number of households per plot.

For risk factors identification for soil plots infestation and children 2 to 10 years in households, Independence Chi-square Test (5\% threshold) was performed. This test also chi-squared distribution or $\chi^{2}-$ distribution with $\mathrm{k}$ degrees of freedom is the distribution of a sum of the squares of $\mathrm{k}$ independent standard normal random variables and is one of the most widely used probability distributions in inferential statistics [20]. About risk factors expressed in the form of dichotomic qualitative variables, the measurement their association force with the ground parasitic and children from 2 to 10 years infestation was made by the calculation of the odds ratio to the threshold of $5 \%$.

\section{Results}

Distribution of surveyed households by health area has hovered around $10 \%$ (data not shown) for each area. An average of $4 \pm 2.5$ households per housing unit was raised and, in the extreme case, a parcel could reach up to $18 \pm 2.5$ households. Moreover, the average number of people and children from 2 to 10 years saved per household were $7.65 \pm 4.2$ and $2.23 \pm 1.5$, respectively (Table 1 ).

In addition, most householders were male of whom a householder on two $(49.5 \%)$ was not owner, and $69.7 \%$ are married or commonlaw. Thirty-five percent of Ngiri-Ngiri health zone householders have completed high school, $22.4 \%$ had an honours diploma, while their spouses $(34.9 \%)$ have not completed their high school education. It shown from this study that $29.5 \%$ of householders had civil servant status in public administration and exercised another activity to buckle the month. Their wives, however, had no occupation $(47.8 \%)$ or exercised petty trade $(30.6 \%)$. The small trade $(35.8 \%)$ is by far the principal source of household incomes followed by the contribution (28.1\%) drawn from the wages of household head. Overall, 241 of 366 households, meaning $66 \%$, are located in unpaved ground plots.

The age distribution showed a higher proportion of girls (51.4\%) compared to boys (48.6\%), with approximately $52.7 \%$ of children with age ranging from 5 to 10 years, and the remnant under 5 years old. The children rate attending school is higher (79.3\%) among children aged 5 to 10 than among 2 to 5 years (51.1\%).

Monitoring load is exerted firstly by moms (25.4\%) follow-up by dads $(11.5 \%)$ who, to $95.1 \%$, wash their children hands as prerequisite before taking any meal.

The majority of households (96.4\%) have latrines which $72.8 \%$ are equipped with septic tanks, $14.7 \%$ are Arab pit type, but without cover. Hygiene of latrines is very significant, more than $61 \%$ of feces uncovered, $33.9 \%$ have soaked paper feces and $55.8 \%$ have latrines overflowing with effluent. As children shedding mode, potties are used by $98.3 \%$ of those under 5 years, while for the age groups of 5 to 10 years, $54.4 \%$ use potties and other access to the bathroom (Table 2).

Effluent management methods are dominated by the evacuation in an absorbing well and in an open hole in the plot, at rates of $34.5 \%$ for both. For households reported owning septic tanks, it turns out that the dump is made directly to the gutter when it rains (45.5\%) or in a hole in the plot $(31.5 \%)$. Moreover, children excreta are removed from the potty in the toilet. Nevertheless, soil plots are infected with parasites at a rate of $45 \%$ while the intestinal parasitic infection was most common $(61.2 \%)$ to the children.

Identification of parasites in soil samples of the plots revealed a dominance of Ascaris eggs followed by that whipworm with $51.2 \%$ and $32.9 \%$, respectively (Table 3 ). In addition, other parasites were also observed. This is the case, for example, of Trichomonas sp. (10\%) and some yeasts nematode (5\%). The analysis of the children's feces revealed the presence of Ascaris eggs, whipworm, yeast or Trichomonas int. at $60.7,16.5$ and $11.2 \%$ rates, respectively.

Infestation rates were generally high in all 8 studied health areas. The surface of Libération health area is that which has the greatest proportion of infested children $\left(74 \% ; \chi^{2}=8.733 ; P=0.272\right)$. However, the age bracket from 5 to 10 years is obviously the group more infested with $61.7 \%$ of parasitized children $\left(\chi^{2}=0.36 ; P=0.850 ; \mathrm{OR}=0.960\right.$ to $95 \%$

\begin{tabular}{|c|c|c|c|c|c|c|c|}
\hline Characteristics & Mean & Median & Mode & $\begin{array}{c}\text { St- } \\
\text { deviation }\end{array}$ & Min & Max & Total \\
\hline Nber of household/plot & 4.08 & 4.00 & 4 & 2.506 & 1 & 18 & 18 \\
\hline Nber of person/plot & 21.55 & 19.00 & 20 & 12.025 & 1 & 72 & 72 \\
\hline Nber of person/household & 7.65 & 7.00 & 6 & 4.219 & 2 & 40 & 40 \\
\hline $\begin{array}{c}\text { Nber of children from 2-10/ } \\
\text { household }\end{array}$ & 2.23 & 2.00 & 1 & 1599 & 0 & 20 & 20 \\
\hline
\end{tabular}

Table 1: Breakdown of households, persons and children in the health zone.

\begin{tabular}{|c|c|c|c|c|c|c|}
\hline $\begin{array}{c}\text { Places of } \\
\text { excretion }\end{array}$ & Children 5 years less & \multicolumn{2}{c|}{ Children from 5-10 } & \multicolumn{2}{c|}{ Total } \\
\hline Frequency & $\%$ & Frequency & $\%$ & Frequency & $\%$ \\
\hline Toilets & 3 & 1.7 & 105 & 54.4 & 105 & 29.5 \\
\hline Potty & 170 & 98.3 & 88 & 45.6 & 88 & 70.5 \\
\hline Total & 173 & 100 & 193 & 100 & 193 & 100 \\
\hline
\end{tabular}


CI 0.630-1.463). Schoolchildren showed highest rates of infestation $(62.6 \%) \quad\left(\chi^{2}=0.276 ; P=0.599 ; \mathrm{OR}=1.119\right.$ to $95 \%$ CI $\left.0.735-1.705\right)$. In addition, a strong prevalence is observed with children whose father, householder, exert a small trade or is a civil servant of the State $\left(\chi^{2}=5.468 ; P=0.7\right)$. Subsidiarity, the lack of occupation for the couple has a link with the high children infestation $(64.8 \%)\left(\chi^{2}=4.420 ; P=0.7\right)$. In addition, the possession and the use of latrines do not influence in any way children infestation $\left(\chi^{2}=0.307 ; P=0.5\right.$; OR $=1.368$ to $35 \% \mathrm{CI}$ $0.45-4.15)$, even less that of households ground $\left(\chi^{2}=2.574 ; P=0.10\right.$; $\mathrm{OR}=2.795$ to $95 \%$ CI $0.756-10.329$ ). Most of infested children (133) lived in household where latrines evacuation was carried out either towards an absorbing well $(70.6 \%)$ or in a drain $(67.8 \%)$, or in a hole open in the piece $(66.2 \%)\left(\chi^{2}=4.507 ; P=0.21\right)$. Nevertheless, it exists a relationship between effluent evacuation location and soil infestation $\left(\chi^{2}=10.458 ; \quad P=0.01\right)$. Most of households which empty their septic pits in a drain after or during a rain or in a hole dug in the piece have presented children infestation rates ranging between 59.0 and $63.0 \%$ $\left(\chi^{2}=1.241 ; P=0.743\right)$ (Table 4).

In addition, the ground and children infestation is independent of their defecation place (OR=1.276 to $95 \%$ CI $0.813-2.003 ; \chi^{2}=1.127$; $P=0.288$ ). On the other hand, there is a strong relationship between children infestation and that of the ground $(P=0.000)$. It however comes out from this study that ground infestation is 4.653 times higher than that of the children (OR=4.655 to $95 \%$ CI 2.904-7.455; $\chi^{2}=43.648$; $P=0.000$ ) (Table 5).

\section{Discussion}

According to OMS [21], public health deterioration is started when previous requirements of domestic waste are not satisfied. The situation is more worsened when population educational level is low, returning

\begin{tabular}{|c|c|c|c|c|}
\hline \multirow{2}{*}{ Parasites found } & \multicolumn{2}{|c|}{ Frequencies } & \multicolumn{2}{|c|}{$\%$} \\
\cline { 2 - 5 } & Soil & Faeces & Soil & Faeces \\
\hline Ascaris eggs & 84 & 136 & 51.2 & 60.7 \\
\hline Trichocéphale eggs & 54 & 37 & 32.9 & 16.5 \\
\hline Anguillules Grubs & 5 & - & 3.0 & - \\
\hline Trichomonas sp. & 10 & - & 6.1 & - \\
\hline Ascaris and Trichocéphale eggs & 11 & 24 & 6.7 & 10.7 \\
\hline Entamoeba histolytica Cysts & - & 2 & - & 0.9 \\
\hline Other (yeast or trichomonas int.) & - & 25 & - & 11.9 \\
\hline Total & 164 & 224 & 100.0 & 100.0 \\
\hline
\end{tabular}

(-) symbols mean lack of data

Table 3: Parasites found in soil and feces of children 2 to 10 years.

\begin{tabular}{|c|c|c|c|c|c|}
\hline $\begin{array}{c}\text { Evacuation } \\
\text { location of } \\
\text { effluent }\end{array}$ & \multicolumn{2}{|c|}{ Soil infestation } & \multicolumn{2}{c|}{ Children infestation } & \multirow{2}{*}{ Total } \\
\cline { 2 - 6 } & Yes & No & Yes & No & \\
\hline $\begin{array}{c}\text { Lost wells in the } \\
\text { plot }\end{array}$ & $34(50 \%)$ & $34(50 \%)$ & $48(70.6 \%)$ & $20(29.4 \%)$ & $68(100 \%)$ \\
\hline $\begin{array}{c}\text { Channel/gutter } \\
\text { Running water }\end{array}$ & $37(62.7 \%)$ & $22(37.3 \%)$ & $40(67.8 \%)$ & $19(32.2 \%)$ & $59(100 \%)$ \\
\hline $\begin{array}{c}\text { Open hole in the } \\
\text { plot }\end{array}$ & $25(36.8 \%)$ & $2(100 \%)$ & $0(0 \%)$ & $2(100 \%)$ & $2(100 \%)$ \\
\hline Total & $96(48.2 \%)$ & $10151.3 \%)$ & $133(67.5 \%)$ & $64(32.5 \%)$ & 1.971 \\
\hline
\end{tabular}

Table 4: Evacuation location of latrine effluent and soil and children infestation.

\begin{tabular}{|c|c|c|c|}
\hline \multirow{2}{*}{ Soil infestation } & \multicolumn{2}{|c|}{ Child infestation } & \multirow{2}{*}{ Total } \\
\cline { 2 - 4 } & Yes & No & $164(100.0 \%)$ \\
\hline Yes & $131(79.9 \%)$ & $33(20.1 \%)$ & $202(100.0 \%)$ \\
\hline No & $93(46.0 \%)$ & $109(54.0 \%)$ & $366(100.0 \%)$ \\
\hline Total & $224(61.2 \%)$ & $142(38.8 \%)$ & 36 \\
\hline \multicolumn{3}{r}{ Table 5: Soil and child selected Infestation. } \\
\hline
\end{tabular}

the latter incompetent to impact positively the country development, even on the behavior as regards of the health [22].

The mean size of observed households in this study is in agreement with what found [23] on the Kinshasa sanitation situation. By cons, the actual average (7.65) is largely higher than the national average (5.4), according to [22]. On the other hand, the number of children by household was larger (2.23) than that (1.3) found by Kiyombo et al. [22]. This testifies the elevated rate in light increase in this town zone, just like of the town suit. However, the values found in this study fit in the range of the national average values recorded in Ref. [14].

The dominating influence of parental guarding on the children health was each time positive, but declined when guarding was entrusted to a third person. Thus, OMS [24] regards health or children care as a paramount concern of the responsible parents. Out an adequate assumption of family health responsibility, as that of the children is conditioned by a minimum income, likely to satisfy the primary education needs. In Ngiri-Ngiri health area, households' income comes in majority from the small trade and also from the wages of the householder which proves to be insufficient to buckle the month According to BEAU [25] report, the public office is the principal employer in Kinshasa. However, Kiyombo et al. [23] located the households' income between 1000 and $5000 \mathrm{FC}$ per day, that is to say 1 to $5 \$$ US, which corresponds almost to the data of this study. However, it is advisable to mention the fragile character of these households because of the low income, which strongly contributes to categorize them in 3 groups, compared to the occupation status in the piece, with the tenants occupying the first rank. Butshia [15] investigation revealed in addition that Kinshasa was placed at the tail of the Congolese cities classification of which proportion householders was weakest. Kiyombo et al. [23] also observed similar results in their study on the Kinshasa medical situation.

With a quite appreciable proportion of the households having latrines with septic tank, however the occupants' medical situation is hardly satisfactory because of the quite high number of households using rudimentary toilets. This spreading to use rudimentary toilets, with the number of which there is the Arab pit without lid, constitutes a royal way of ground and underground sheet contamination, that is to say a process which is non hygienic and hardly makes it possible sufficiently to separate the excreta from the ambient conditions [26]. The results of this study however differed from those evoked in the above-mentioned report.

The distance between housing with latrines $( \pm 15 \mathrm{~m})$ could constitute a factor supporting the ground and children infestation especially when it is considered that distance between housing and latrines, coupled with characteristic low income of households in NgiriNgiri health zone, could represent a limit with the alteration work of the adequate hygienic installations [27]. In addition, the latrines' draining mode would influence significantly germs proliferation because only a-fifth of households resort to the services of trucks draining and the remainders pour the excreta in the gutter or a hole dug in the piece. Consequently, low level and/or lack of precaution in the excreta evacuation and other effluents of latrines would contribute to degrade public health, according to OMS [28] report. However, it should be announced that the results of this study are superior with those found in Kinshasa sanitation investigation [23].

Lumbricoides and Tricocephales eggs in majority were observed on ground samples because of mainly excreta bad management. This excreta bad management would explain fast and wide parasites dissemination on the whole household soil [29]. Results much more alarming were found in a similar study in Madagascar where the 
prevalence of ground infestation reached 93\% for Ascaris lumbricoïdes and 55\% for Trichirus trichura [30]. In addition, Al-Mekhlafi and Smith et al. [13,31] found, for their part, that the transmission of helminths eggs by the ground constituted a problem of public health in Malaysia in the children from 2 to 15 years of age, and in Mindanao, Philippines, in students of secondary school [32]. Almost the same age bracket (2 to 12 years) underwent the most intense infection by Ascaris in Honduras at the time of a study on the prevalence and the infection intensity of Ascaris lumbricoïdes on 240 samples of feces, brought back Smith et al. [31].

In a total way, Ascaris prevalence increases in the world, mainly in the tropical and subtropical area (Southern-east Asia, Western and Central Africa, as in China) where it could exceed $39 \%$ in certain cases [33]. The estimate reveals that more than one billion and half of people are infested and that approximately 2 million are in risk to be infested. In addition, Crompton and Amato et al. consider that the tendency to the increase in these areas is supported by heat and the high percentages of atmospheric humidity, favorable to the propagation and the development of Ascaris and other parasites [34]. However, Lanoix and Roy [35] shows that the delay with the installation of measurements allowing a correct evacuation of excreta and the adaptation of hygiene rules lead to serious vexations to the health level by contamination of soiled hands and untreated rejections.

In conclusion, it comes out from this study that the high number of households per piece $( \pm 5)$, with a precarious monthly income (small trade, income of the state civil servant householder), an overdrawn school education (only one-fourth of the university graduates), contribute to increase the level of ground and children from 2 to 10 years infestation. In addition, excreta and effluents bad management is quoted as at the base of the infestation prevalence of ground and children and is regarded as a factor of significant risk. That induces a strong proliferation of pathogenic agents, in fact Ascaris and Trichocephales. To cure this situation is equivalent redefining the overall policy of urban development and that of the national program of cleansing, rehabilitating and justifying the brigade of hygiene for a population effective framing by an education of mass, particularly centered on the management of households excreta, and finally, facilitating the granting of the appropriations intended to finance the construction of medical with septic tank in favor of the stripped households.

\section{References}

1. Ngnikam E, Tanawa E (2006) African cities facing their wastes. University of Technology Belfort-Montbeliard, Belford.

2. http://www.fne.asso.fr

3. CEE (1993) The environment in Europe and North America, Discussed Statistics 1992. Statistical standards and studies, Nations Unies, New York, USA.

4. Guibbert JJ (1996) To a significant and lasting change in third World cites. Proceedings of the 2nd Scientific Workshop of the network of environmental law of AUPELF- UREF at the University Cheikh Anta Diop in Dakar, Senegal.

5. Fatouma SB (2004) Clean technologies. Waste treatment and Evacuation of Ecological, Crepa, Burkina Faso.

6. Cairncross S, Hunt C, Boisson S, Bostoen K, Curtis V, et al. (2010) Water, sanitation and hygiene for the prevention of diarrhea. International Journal of Epidemiology 39: 193-205.

7. Duncara M (1994) Low cost of urban sanitation. Wiley ET Sons, Paris.

8. Mutonkole SP (2015) Benthic Macro invertebrates as Indicators of Water Quality: A Case-study of Urban Funa Stream. Open Journal of Water Pollution and Treatment 2: 8-24.

9. Perrine D (2002) Pole urban social development. Flammarion, Paris
10. Van Depite (1984) Medical Helminthology. Paris.

11. OMS (1997) Drug used in parasitic diseases. Geneva.

12. OMS (2000) Diseases affecting children. Geneva.

13. Al-Mekhlafi MS (2006) Prevalence and distribution of soil-transmitted helminthiase orang Asli children living in peripheral. Prevalence and distribution of soil-transmitted helminthiase orang Asli children living in peripheral Malaysia 37: $40-47$.

14. UNICEF (2001) National survey on the situation of children and women (MICS 2). Kinshasa, DRC.

15. Butshia M (1998) The problem of disposal of human excreta and its impact on the environment. Medelingen, Kinshasa.

16. Lelo NT (2008) Kinshasa, city and environment. Harmattan, Paris.

17. Jayaraman K (1999) Statistical Manual for forest research. EC-FAO.

18. Sokpon (1995) Ecological research on semi-deciduous dense forest Pobé southeast of Benin: plant communities, structure, natural regeneration and litter fall. Thesis ULB, Brussels OMS (1982). Basic Technical Manual for the Medical Laboratory, Geneva.

19. https://en.wikipedia.org/wiki/Chi-squared_distribution

20. OMS (1989) Improving environmental health conditions in habitats. Geneva

21. Ministry of Planing and Macro International (2008) Demographic and Health Survey. Democratic Republic of Congo, Calverton, Maryland, USA.

22. Kiyombo M, Kalambay H, Konde N, Pindi K, Diwete L (2005) Analysis report on the health situation of the city of Kinshasa, Kinshasa.

23. OMS (1996) The road to health for a sustainable world. Geneva.

24. Employee (2014) Forward for reform, a new modernization of the public administration strategy. Ministry of Public Service, Kinshasa.

25. PNUD-RDC (2015) Political inequalities, Socio-economic and building of Nation/State in the Democratic Republic of Congo. UNDP - Kinshasa.

26. Lanoix JN, Roy ML (1976) Sanitary technician in a precarious position. WHO Geneva.

27. OMS (2006) Sanitary technician in a precarious position. WHO, Geneva.

28. http://www.journals.plos.org/plosmedicine/article?id=10.1371/journal pmed.1001162

29. Kightlinger LK, Seed JR, Kightlinger MB (1998) Ascaris lumbicoides intensity in relation to environnemental, socioeconomic, and behavioral determinants of exposure to infection in children from southeast Madagascar. The Journal of Parasitology 3: 480-448.

30. Smith HM, Dekaminsky RG, Niwas S, Soto RJ, Jolly PE (2001) Prevalence and intensity of Ascaris lumbricoides and Trichuris trichuira and associated sociodemogaphic, Honduran. Rio de janeiro 96: 303-314.

31. Sumagaysay JB, Emverda FM (2011) Eosinophilia and Incidence of SoilTransmitted Helminthic Infections of Secondary Students of an Indigenous School. Asian Scientific Journal.

32. De Silva NR, Brooker S, Hotez PJ, Monstresor A, Engels D, et al. (2003) Soiltransmitted helminth infections: updating the global picture. Trends Parasito 19: 547-551.

33. Crompton DW (1999) How much human helminthiasis is there in the world. $J$ Parasitol 85: 397-403.

34. http://waojournal.biomedcentral.com/articles/10.1186/s40413-015-0073-0.

35. Lanoix JN, Roy ML (1994) Sanitary technician in a precarious situation. WHO, Geneva. 